\title{
Green Marketing: Role of Psychographic Variables on Awareness and Purchase of FRP Products
}

\author{
Dr. Mrs. Mala Kuthiala ${ }^{1}$, Dr. Prof. Sadhana Mahajan ${ }^{2}$ \\ ${ }^{I}$ (School of Management, Bahra University, India) \\ ${ }_{2}^{2}$ Himachal Pradesh University Business School, Himachal Pradesh University, India)
}

\begin{abstract}
The present exploratory and empirical research paper is based on the growth of interest on "Green Marketing" particularly "Green buildings" and consequently to analyse the application of the concept of green products related to psychographic factors. It attempts to analyse the impact of psychographic variables such as perception, attitude, learning, motivation and personality on the awareness and purchase of one of the green product: FRP (Fibreglass reinforced plastics) products.

Accordingly, the research methodology was framed with the thought that many marketing problems can be solved today by looking beyond the secondary data so as to give an insight into the behaviour of the consumers. The questionnaire for primary data collection was presented to 700 respondents out of which received back only 550. For analysis of data, 200 questionnaire of those respondents who were aware of FRP material, and were the residents of Himachal Pradesh who took part in the decision making process regarding the purchases at the residential level. Hypothesis was framed regarding the impact of psychographic variables on the awareness and purchase behaviour of the consumers and the potential of these products. After the analysis of results the hypothesis related to psychographic variables was partially accepted.
\end{abstract}

Keywords- Consumer Behavior, Fibreglass Reinforced Plastics, Psychographic Variables, Green Marketing, Green Products.

\section{INTRODUCTION}

For framing green marketing strategies, according to Dakode \& Yerkari [1] (2012. p. 415), one of the goals of green marketing is to reinvent the concept of product and thus one of the most important benefit is to ensure long term growth along with profitability by helping companies markets their product and service keeping the environment aspect in the mind. They concluded that, "Green Marketing provides an opportunity to the companies to increase their market-share by introducing eco friendly products" (p. 417). Jethani \& Uttarwar [2] also quote 2012, p. 1375) in their research study as per the need of today's era is, "an eco marketing campaign should have several important factors in order to ensure long-term sustainability.

The growing interest in green concept made Kotlar, Kartajaya and Seiawan [3] to write, "These trends are moving green buildings into mainstream markets" (, 2010, p. 165). They further summarized that they underscore the importance of value based companies moving towards a green commitment.... Companies that promote environmental sustainability are practicing Marketing 3.0. They also vividly summarized that “ $\ldots$ the era of Marketing 3.0 is the era where marketing practices are very much influenced by changes in consumer behaviour and attitude." (p. 21). In India too, Bhardi [4] (2012, p. 1093) quotes, "Several organizations responded to this by applying green principles to their company such as using environmental friendly raw materials, reducing usage of power."

The increasing concern today, of Green concept has lead to the question of actual application of the concepts of green technologies leading to green marketing for the promotional role of green products for example the FRP (Fibreglass reinforced Plastic) products in developing construction of structure and infrastructure. For this it is essential to understand the impact of consumer behaviour and its variables on the green marketing of these products. Green marketing is a marketing strategy involving an emphasis on protecting the natural environment. (Soloman, [5] 2011, p 623,) and promote healthy, reusable and eco friendly products (Schiffman, Kaunf and Kumar, [6], 2010, p.479; Dakode \& Yerkari, 2012, p. 414). It can also be termed as sustainable marketing, environmental marketing or ecological marketing.

US Green Building Council [7], developed LEED ${ }^{\circledR}$ as a voluntary, consensus- based national standard to support and validate successful green building design, construction and operations and organizes industry Green Build International Conferences and Expo ("A National Green Building Research Agenda", 2007) [8]. The LEED Rating System (Leadership in Energy and Environment Designs) is proposed as per IGBC (Indian green Building Council) at Hyderabad for construction and development. Its first rating programme is development for residential sector in India. It covers methodologies to cover diverse climatic zones and changing lifestyles. It is based on the accepted energy and environmental principles and strikes a balance between known established practices and emerging concepts. (Sahasrabuddhe, Bhole and Deshpande, [9], 2012, 
P.69). According to them the concept 'Green home' in addition to providing energy efficiency environment also is less expensive over the long run and more enjoyable to come home to.

Supporting the concept further Kuthiala and Mahajan[10] (2012) says , "According to CII website a green building is similar in functionality and appearance to the convectional one but the difference is in the approach. The focus is on resource conservation and increase work productivity, by influencing the outdoor as well as indoor eco- friendly environment. Green Building is a dynamic, rapidly growing and evolving field driven by confluence of rising public concerns about global climatic change, cost and availability of energy sources, and the impact of the built environment on the human health and performance,"

The fast technological revolution thereby is giving rise to the fast changing and newer materials. The ministry of New and Renewable Energy introduces schemes with programmes for development. A press release [11] (PTI, 2008) also revealed that, "The union ministry of new and renewable energy is in the process to introducing a rating system for buildings, based on energy efficiency installed in there.... The ministry wanted the system in place before the end of this year." This system gave additional benefits and frame support polices to organizations which are promoting eco- friendly products.

And, one of such materials is Reinforced Fiberglass Plastics (FRP or GRP) or composite material as it does not have an effect on the ozone layer. This is supported by reviewing the scientific literature which clearly points out “........Fiberglass board do not deplete ozone", Wilson, [12], (2001, p .161) specifies non -ozone depleting roof insulation in an Energy, Environmental and Economic Resource Guide. In another application Master and Ela [13], (2008, p. 243) quoted, "Fibreglass Insulation...... also contains no CFCs". Thus we have selected this material studying the impact of psychographic variables on awareness and purchase.

Fiberglass Reinforced Plastic, is a polymer based technologically advanced and revolutionary material which offers many advantages over the traditional materials chief among them are- optical translucency, formablility, high strength, light weight, flexibility in design parts, consolidation, high dielectric strength, dimensional stability, corrosion resistance and low tooling and maintenance costs (Thapar, [14], 2008, p.2). Many international researchers (Finger, [15], 1972; Mc Garry, [16], 1970) in the past have been stating importance on the role of Fibreglass Reinforced materials in building systems. Even in this century, the research works (Kurkjian \& Matthewson, [17], 2007; Ryvkin \& Aboudi, [18], 2007; Neto \& Rovere [19], 2007; Mouhmid et al, [20], 2006; \& Giraldi et al [21], 2005) based on the utility of these products is on full swing in various applications.

In India, NIIR - National Institute of Industrial Research, [22], consisting of consultants and engineers, published many books on polymers and the resin materials. The book, The Complete Technology Book on Fibre Glass, Optical Glass and Reinforced Plastics, 2007 written by NIIR reviewed as, "Although many natural materials were used in the past by man, answering his instinctive urges to prevent heat loss from or entry into his dwellings, no material in modern technology has satisfied the all around requirements as has fiber Glass. Fiber glass, Optical glass and reinforced plastics have important applications and uses in the making of various products." Bakshi and Sir Lal, [23], Professor of Chemistry, University of Delhi (2007, p. IT-7) quotes, “........ with the advantages of polymers such as light weight, great workability, resistance to corrosion and low cost have such a vast scope of diverse applications and these are being called the materials of 21 st century." Hence materials like this which when used have the properties of not only saving energy resources, but also reducing the life cycle cost keeping in mind the mould ability of the product as per the requirement of the customer, thus can be termed as green product. Therefore for our research purpose we have chosen FRP products and their awareness and knowledge of properties with relation with the psychographic behavior of the consumers of Himachal Pradesh, which in turn affects their purchasing behavior.

The need for such research paper is further aggravated because of the fact that there has been a question mark and gap between the planning and implementation of green concept. Sahasrabuddhe, Bhole and Deshpande, (2012, P.67) stated clearly that "The use of Ecosystems for recreation, wealth enhancement and other selfish purpose is growing." They further stated that, "It is called a solution, technique, an attitude, or a lifestyle turning GREEN is possibly the only way out of this mess we have created ourselves for." Laroche, Bergeron and Barbaro-Forleo [24], (2001) reported that although today's ecological problems are severe, the corporations do not act responsibly towards the environment and that behaving in an ecologically favorable fashion is important and not inconvenient. From the consumer point of view, Bonini and Oppenheim [25], (2008), D'Souza, Taghian and Lamb [26], (2006) and Yam-Tang and Chan [27], (1998), results have shown that consumers' environmental concern is not reflected in their purchasing behaviour. "Environmental concern is still not a strong motive for majority of these well-educated respondents to purchase eco-friendly products" quotes Anjankar [28] (2012. p.66) in the empirical research work.

The presence of the towns turning into concrete jungles is the result of decisions being taken on subjective assessments and are made without regard to other conditions like, environment, climatic changes, future implications and health conditions. Ananth [29], (1999, p. 56) writes, "Nowadays in the contemporary neighbourhood, it has become common to build without any reference to either the already existing structures or the natural environment. Hence some buildings stand out like sore thumbs, blatantly alien. This may seem like 
'fun', 'progressive', and 'innovative', but the impact of something so alien can have very disturbing results on the occupants of such a building." These structural and architectural decisions often produce unreliable results and do not lead to optimal solutions. Hence, seeing present situation it is clearly evident that the basic concept of consumer, marketing research and strategy formulation and implementation based on the understanding of the behaviour of the consumer is lacking.

Although many researchers today, Anjankar, (2012), Jose and Helena, [30], ( 2012), Chopra \& Marriya, [31], ,(2012), Bhardi, (2012,) have based their research on eco- friendly products in general, Chopra \& Marriya (2012, p.809) believe that, "Green marketing is still in its infancy and a lot of research is to be done on green marketing to fully explore its potential." This calls for more research work to gain knowledge into the insight of consumers. The need of an hour is initiation from educational and academic experts, government and businessmen to induce people to channel their efforts towards implementation of authentic Green marketing and illumination of "greenwashing" concept.

One of the other ways to counter this problem is to enhance the application of new innovative eco friendly or greener materials (Jethani \& Uttarwar , 2012, p. 1374) in construction, which are technologically advanced by understanding the behavior of the customers, their needs and then trying to relate them with the properties fiberglass products and finally communicate to the consumers the effect that these products have on conservation of different energy resources. Therefore, highlighting the "green value" of the FRP products due to their distinct properties with their advantages can influence the attitude and perception of the potential consumers. For which understanding of psychographic variables of the consumers can play a vital role in formulation of Green marketing strategy

Kotler et al [32], (2009, p. 80) had stated three key principles for avoiding Green Marketing Myopia given by Ottman et al, [33], 2006 as Customer Value Positioning, Calibration of Consumer Knowledge and Credibility of Product Claims. Understanding these issues would surely aid the industry of reinforced plastics to adapt strategies by taking the consumer into consideration. It is also understood that consumers will sometimes be persuaded more by logical arguments, but at other times will be persuaded more by emotional or symbolic appeals. By understanding the consumer, it will be possible to make a more informed decision as to which strategy to employ to the particular category of customers.

While not quite a household name FRP has worked its way into a seemingly endless number of applications. (Kuthiala, [34], 2012, p. 611) Hence, marketing activities especially based on the consumer behaviour analysis can prove to be vital in growth and expansion of these products. This paper is an attempt to understand the impact of Psychographic variables on awareness and purchase of various FRP products.

\section{OBJECTIVES}

Keeping the above concepts as a base, the following objectives are framed for the current research study.

1. To comprehend the impact of psychographic variables like perception, attitude and learning on product benefits sought by the consumer.

2. To predict the future potential for the expansion of FRP products.

\section{RESEARCH METHODOLOGY}

"In today's technology, driven business environment many marketing problems, can be solved by looking beyond secondary data" (Hair, Bush, and Ortinare, 2008, p. 175) [35]. This thought resulted in designing a research methodology for collecting and analyzing the primary data for providing the decision makers with current real time information and observations of consumer behaviour. It consisted of the following steps:

\subsection{Hypothesis}

In the background of overall objective of the study and after review of existing secondary data, the following hypothesis has been developed.

H. Psychographic variables like attitudes, perception, personality, learning and motivation would have a significant impact on the awareness and purchase of the different application of FRP products.

\subsection{Sample}

The universe, for the exploratory and empirical research study was the consumers and potential consumers of Himachal Pradesh, and the sample was collected from the capital, Shimla. Non probability and convenience sampling are used. Random sampling was used while selecting the data. The data from residential sample was collected for this study, from the respondents who make the decision for purchase of various products. Sample size of 200 respondents was taken for the study. Questionnaire was presented to 700 respondents randomly, out of which received back only 550 filled up questionnaires. Out of 550 respondents 
200 were aware of FRP products. These respondents were people according to themselves, who took part in the decision making process regarding the purchases at their respective homes.

\subsection{Data Collection}

A self framed and developed questionnaire with both closed and open ended questions was used to collect the data. The questions contribute to psychographic variables consisting of product properties and subsequently reflecting respondent's knowledge leading to consumer benefits sought and thus giving valuable insight into the awareness and knowledge level of the respondents who could be the potential consumers in the future.

\subsection{Data Analysis}

Both descriptive and quantitative analysis of the study was undertaken. For descriptive analysis the assessment of answers from the questionnaire were done to identify the major variables which would have a significant impact on the awareness and purchase behaviour of the potential consumers. The quantitative analysis of the data was undertaken by using both Microsoft excel and SPSS (Statistical Package of social sciences). The data was organized into an easily assimilated, tabulated, understandable form and various statistical and mathematical tools were used for analysis.

\section{RESULTS}

The data analyzed for this research study, consisted of 200 Questionnaires, which were filled by the respondents who were aware of FRP Material. $36.36 \%$ of respondents were found to be aware of FRP material. The results on the following psychographic variables studied in this paper are given below:

Psychographic variables: Attitude, a psychological variable, is related to the consumer's predisposition to respond to a product. Beliefs (about the objects strength and economy), emotions (feelings- like and dislike) and readiness (of the individual to buy) are the three elements together called upon to form the image of the FRP products. Hence, the consumer image refers to the result of many individual attitudes towards the various FRP products. Awareness and knowledge of the different types of old and new construction materials used for structural development is the first step to form the belief, emotions and readiness towards those products. The data reflected the awareness of different construction products presently used. Out of the old construction materials only wood has $100 \%$ awareness. Whereas iron and cement have $90 \%$ and steel $80 \%$ and tin have as low as $69 \%$, as per the primary data collected for construction materials.

After the awareness of construction materials, the awareness of various FRP products was analyzed. The data clearly indicates that out of 24 FRP products which are taken in the Questionnaire, the maximum awareness is of roofing sheets that is $82.5 \%$. This is followed by water tank and bathtub. Then the awareness of application of FRP in various sectors was assessed. The result found that $91 \%$ respondents are aware of the fact that FRP products are used in construction industry. Whereas $76 \%$ respondents are aware that it is a versatile product for interior decoration. 67 and 66 percent of respondents are aware of usage of FRP products for agriculture/ horticulture /floriculture and electrical industry respectively. Only $55.5 \%$ respondents are aware of its usage in marine and transport industry. Less than $50 \%$ respondents are aware of its use in entertainment industry and defence.

The next part of questionnaire was framed to analyze the knowledge of FRP composite material by analyzing the awareness of it properties which give it various advantages over the conventional materials used. Out of twelve properties of FRP products only $30 \%$ of the respondents were aware of properties between 10 to 12 and $30.5 \%$ were aware of 7-9 properties of FRP products. 29.5\% respondents were aware of 4-6 properties and $10 \%$ were aware of less than 3 properties. Maximum percentage that is $81.5 \%$ respondents are aware of the property of Durability, (Finger, 1972) long life and best material for glasshouses by protecting plants from adverse conditions and simultaneously providing with sunlight for their food and growth. $75.5 \%$ respondents were aware of the fact that this material can be made translucent for penetration of maximum sunlight indoors (Mc Garry 1970). And 70\% of respondents are aware that FRP products are unbreakable and hence are ideal material for substitution of conventional glass. $69 \%$ respondents are aware of its waterproofing property.

Only $64.5 \%$ are aware that FRP products are light and strong, hence making it an ideal material for transport industry and has virtually replaced convectional materials in this field. 58\% respondents are aware that it is revolutionary material for interior decorators, because of its ability to mould into any shape and design (Sănchez \& Jorge [36] , 2005) as per the requirement to meet the needs of the customers, in addition to it a light and strong material and hence easy to maintain and long lasting. Its property of laminating working table-tops has only $56 \%$ of awareness. $52.5 \%$ awareness for its property of usage on main gates to maintain privacy and its ability to be chemically inert making it corrosion resistant (Mc Garry, 1970) when compared with wood and steel. Approximately half of the respondents who are aware of FRP products are aware of its sound - proofing property and only $39 \%$ are aware that it is an ideal material for making fountains 
Long life durability is the FRP property which is ranked first by the customers who purchased FRP products and sheets. Bathtubs purchasers, ranked strength on the scale of importance as the first property to affect the decision making activity. Strength is ranked second by the FRP product and sheet purchasers. Whereas in the case of bathtub purchasers they ranked design variability and moulding as the second property. The third aware property in all the purchasers of FRP product is it advantageous of being light in weight, whereas in the case of FRP sheet purchasers, it is high quality.

To further understand the intensity with which the respondents feel about the properties of FRP products, the respondents were asked to rank the eight statements. When all the eight statements are taken together, the maximum number of respondents partial agrees with the statements, followed by indifferent attitude towards FRP Products. The gap between these two levels of strong agreement and indifferent attitude is very less, nearly insignificant, hence nearly bringing them at the same level. There is a significant drop in the figures of disagreement levels. Nevertheless the data is positively skewed towards agreement side.

Among the seven marketing variables design, price, quality, thickness, availability, fulfillment of personal requirement and environment friendly, the variable ranked first by the respondents in this region is quality, with the ranking position of 1.51 that is on the scale ranking between extremely and very important categories. This is followed by environment friendly at 1.68 ranking, hence a clear reflection of the fact that people of this area are both quality and environment conscious.

\section{INTERPRETATION OF RESULTS}

This study tried to unveil the area of consumer behaviour with impact of the different psychographic variables on the awareness and knowledge of Fibreglass application and properties leading to customer satisfaction and expectations, and its relationship with various parameters through structured and customized market research techniques (Sathish and VenkatramarRaju, [37], 2012, p 115).

Psychographic variables: After interpreting the results of the study it was found that psychographic variables like perception, attitude, motivation and learning do have a significant effect on the awareness level. Whereas the type of personality trait reflected does not significantly affect the awareness level of FRP products. The purchase level of the customers is however affected by the personality trait. The increased percentage of purchase of FRP products is made by price conscious trait of the customers, hence making FRP products into prestige products.

Perception of the customers is based on the awareness of the material, on which the consumer develops attitudes towards the products depending on the basic personality traits of the consumers, which in turn are influenced by the internal learning and motivation factor and external factors as cultural, social, geographic and demographic ( Kuthiala, [38] 2012, 849) etc. To analyze the awareness of the material used two categories that are conventional and new material is taken in this study.

5.1 Conventional materials: This data reflects that the perception of the people towards construction material such as tin is $69 \%$, because they do not give it much thought as it does not interest them much for the creative use in the construction, interior designing and the other growing industries in the present world. Whereas wood seems to be the most preferred construction material from the attitude of the consumers of Shimla, as far as old construction materials are concerned. Which is confirmed by Singh [39] , (1997, p.193), "The ancient art of Himachal Pradesh has survived in the form of temple architecture, wood carvings........The most ancient art and architecture of Himachal Pradesh is in Khasha style and the basic material used is wood."

This can be due to its properties and also because of its abundant availability in the mountains. As Kansal \& Paliwal [40] (2012) quote "When these raw materials are natural, such as wood, laws and good environmental citizenship require that the business take measures to replace what it uses"(p. 877). Thus highlighting the present situation, in which it is very important to prevent the ecological balance, it is not possible to use wood as a construction material on large scale to meet the requirements of the growing population of the mountains. Thereby, making it extremely significant to scientifically study the advantages and properties of technologically new revolutionary construction materials and make efforts to increase their awareness and acceptance among the consumers. As far as, iron, steel, tin and cement are concerned, they are old materials and it is not possible that the consumers are not aware of them, we can presume from the data that these materials traditionally are less popular in the mountainous regions.

5.2 New construction material: The primary data reflects that reinforced Fibreglass has 100\% awareness, because only that data of people were analyzed that were aware of reinforced fiberglass plastics products. Whereas if we judge in totality out of 550 people only 200 were aware of FRP products, giving the percentage figure of FRP products as only $36.36 \%$. This, itself indicates the potential which is untapped of this product. There is a significant drop in the percentage of people aware of new construction materials as compared to the old construction materials. Out of these polycarbonate has $29 \%$ awareness and acrylic has $31 \%$ awareness. Hence it directly reflects the immense scope in educating the consumers about utility of FRP products. In order 
to change the attitude and perception of the consumers, highlighting the advantages and useful properties of the new construction materials can play a very important role. The following data from the census 2001, throws light on the attitude towards usage of FRP products.

The limited use of new construction materials can be supported by the figures. In the category of material used for the construction of roof, [41] ("Summary of table..." Table S02-004, H-3A India), plastic and polythene material has only $0.4 \%$ share that is only 8000 households have used these products from total 24 lac houses. The use of these products is only $0.3 \%$ in the rural area as against $0.9 \%$ usage in urban areas. Slate has been used maximum for the roofs with $45 \%$. In the rural areas the usage of slate for the roof has been maximum that is $49 \%$, whereas in the urban towns it is only $9 \%$. In the urban areas concrete roof has maximum percentage of $61 \%$, followed by G.I., Metal and Asbestos sheets with $22 \%$. Grass, thatch, Bamboo, wood, mud etc have $13.1 \%$ share out of total houses. In the rural area it has higher percentage of 14.2, as against 3.6 in the urban areas.

In the other table showing the data for distribution of houses by predominant material of walls, [42] ("Summary of table..." S02-005: H-3B India), the use of plastic and Polythene material is only $0.2 \%$. The urban area shows $0.6 \%$ usage whereas the rural area shows only $0.2 \%$ usages. The highest percentage of usage in the walls is with stone material showing $42 \%$ in the total data, with the breakup of $45 \%$ in the rural area and $12.6 \%$ in the urban area. In the urban area burned brick has the highest percentage of $70.1 \%$, and in the rural area stone shows the maximum usage. Mud and unburned brick also shows a high percentage of $27.5 \%$. In the urban areas concrete wall are also used, having $3.4 \%$ share.

Among the materials used for floor [43] ("Summary of table" S02-006: H-3C India), Plastic and polymer based material has no percentage of usage in 2001 census data. In the overall data mud has the maximum percentage figure of 55, being more commonly used in the rural areas with 59\% share. Whereas in the urban area it has only $11 \%$ share. The most popular material used for the floor in the urban sector is with cement, having $79.9 \%$ share. Other materials which are also used for floor are wood and Bamboo, which is more common in the rural area with the percentage of 10.6, as against only $2.9 \%$ usage in the urban sector. Mosaic floor tiles have a higher share in the urban area with $3.8 \%$ as against 0.55 in the rural areas

The figures of census 2001 are clear indicators of the vast scope and potential of the green products like FRP composite (Kuthiala, [44] 2012, p. 46) in this region. The data indicates that there is not any significant difference in the percentage of awareness between the different customer segments of FRP products awareness and purchase on the basis of knowledge about construction materials. The confused knowledge of FRP products is evident from the fact that $90 \%$ of the customers who purchased FRP products, sheets and bathtubs where aware of the fact that it is made of FRP material.

The analyses of the primary data revealed that people of Shimla are a perfect example of Instrumental conditioning of learning between two stimulus, that are wood and preference of construction material. Initially wood was the unconditional stimulus. Over the years, after its constant usage and due to the satisfaction of the consumers, it turned into conditional stimulus, for any construction and infrastructural works. The diagram (Fig. 1 ) is used to explain this behavior of the respondents. The desired behaviour is learned over a period of time, as intermediate actions of repurchase which act as a reward in the process of Shaping. In Instrumental learning the response is performed because it is instrumental in gaining a reward. In this case, the satisfaction of the consumers acts as the positive reinforcement, because the people over the time choose wood as their most aware construction material.

$$
\begin{aligned}
& \text { Initially } \\
& \text { Stimulus --------------------»»»»»» Consumer -----------------»»»»»»Response } \\
& \text { Usage as } \\
& \text { a construction material) }
\end{aligned}
$$$$
\text { (Wood) (Satisfaction after } \quad \text { (Leads to repurchase) }
$$

\section{FIGURE 1: A conditional stimulus in construction-a behaviourist's perspective of learning with wood}

The motivational factor, which influences observational learning are the result of usage and applications of FRP products based on the personnel requirements of the customers of this mountainous region depending on their psychographic, economic and geographic conditions. The process that causes people to behave as they do, in order to satisfy their need refers to motivation. In the case of FRP products the need 
aroused may be utilitarian, that is desire to achieve some functional or practical benefit, or it may be hedonic, that is can be an experiential situation, involving emotional responses or fantasies.

Observational learning can also be of significant help, as deciphered by researcher's observation during the data collection. The concept of observational learning in this case has been illustrated with the help of the following process sequential diagram (Fig. 2). The personal and cultural factors combine to create a want, which is one manifestation of need. With the knowledge of advantages and advanced properties of FRP products, a stage of discrepancy can be created between the consumer's present stage of infrastructural development and the ideal stage of structural development. The drive or the degree of arousal in the consumer will determine the urgency the consumer feels to reduce this tension. Hence motivational factor for the FRP products can be described in the terms of strength, or the pull they exert on the consumer by their added advantages, and its direction, or the particular way the consumer uses FRP products to reduce motivational tension by satisfying his needs and wants. However the needs and wants of each person may be different and FRP products being versatile in nature can be created in many ways to satisfy these different needs.

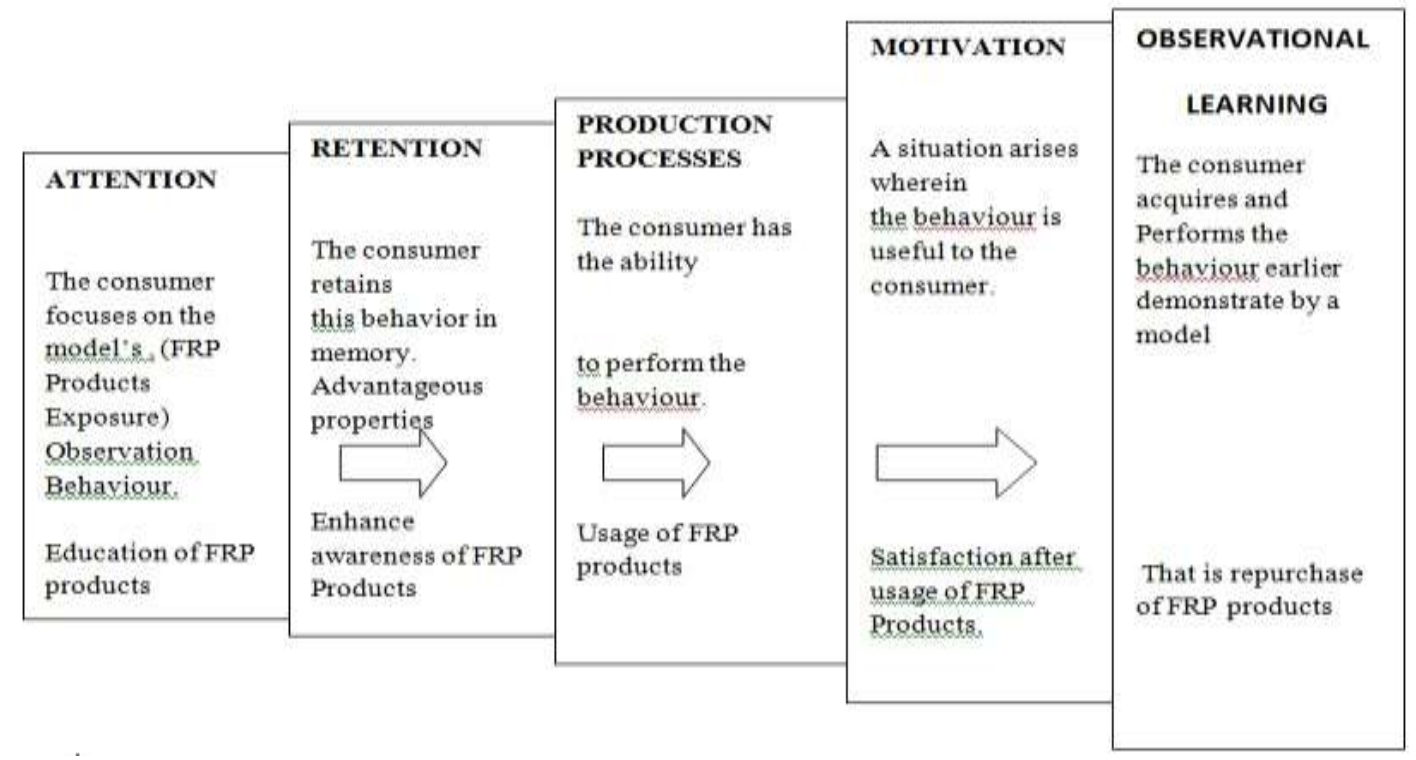

\section{FIGURE 2: COMPONENTS OF OBSERVATIONAL LEARNING FOR EXPANSION OF AWARENESS OF FRP PRODUCTS}

According to the primary data collected for this study, there is reflection of more influence of personality traits (Darten and Perrcault Jr, [45] 1975) of self confidence and fashion consciousness among the people aware of FRP products in this region, over the other traits. The maximum percentage of marks are of self confidence, followed by fashion consciousness, a tie between price consciousness and art enthusiasm at third position, and the minimum percentage goes to new brand tries. Singh [46] (1988, p. 119) describes, "The people of Himachal Pradesh are amongst the most delightfully colourful in the world. They are humorous and light hearted even in adversity, and are fond of good living and almost entirely without guile".

As per the results of the research work, the dough graph (Fig. 3) does not reflect a significant difference in awareness of FRP products in respondents with different personality traits. Hence signifying that it is more important to make marketing strategies for promotion of FRP products in this region, which highlights important properties for different usages and applications with innovative designs of FRP products rather than giving more importance to the price. Nevertheless it is important that the price has to be affordable as income reflects to have significant impact on the purchase of FRP products. A good marketing strategy as per the personality traits of the people of Himachal Pradesh has to be based on their needs and requirements that is pointing out to highlight the advantages over the traditional construction materials, rather than to be based on other factors like price, fashion and art. Hence learning and educational techniques would be of significant importance in the marketing of the different FRP products. 


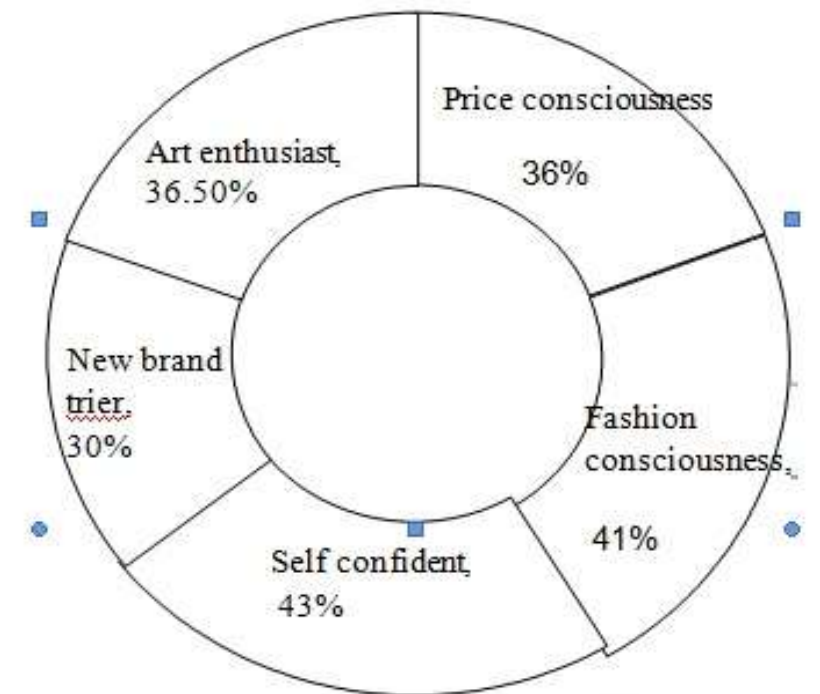

FIGURE 3: AWARENESS / PERSONALTY TRAITS

Among the customers who purchased FRP products, sheets and bathtub the personality trait of price conscious has the maximum percentage with respect to other personality traits. Anjankar (2012. p.66) research study also supports this as it concludes that, "It is worth noting that respondents exhibit low levels of willingness to pay a premium price for eco-friendly products, suggesting that green marketers in India may likely consider cost cutting strategies." In addition to cost cutting strategies for a material like fiberglass it is important to lay emphasis on the life cycle cost analysis.

The research study by Jose and Hena (2012) concludes that, "initial investment cost of green construction project is around $10 \%$ more than the conventional construction project. But the saving occurring over the six year period is around $12 \%$ more than conventional construction. Similarly there are reduced operating and maintenance costs of about $5 \%$ (p. 39).

This is followed by the personality trait of self confidence." This fact is further supported by the following studies (Erickson and Johansson, [47], 1985; Lichtenstein et a,1 [48], 1988; Tellis and Gaeth [49], 1990), stating that price of products may have a positive role in determining the perception of quality. These studies revealed that consumers often used the price cue as evidence for judging quality when choosing between different brands. In practice, a higher price would infer a higher level of quality. In addition, research (Lichtenstein, Ridgway, and Niemeyer, [50], 1993) which suggested that consumers who perceived price as a proxy for quality, also perceived high prices as a positive indicator suggesting a certain degree of prestige. The result of the present study supports this view point too as there is very little difference in the respondents in the category of price consciousness and self confident. Hence highlighting the concepts of quality, prestige and status in the promotional strategy of FRP products in this region, would have positive impact.

Very few respondents disagree with the FRP properties and maximum people partially agree with its properties. This is a clear reflection that even among the people who are aware of FRP products, very few people are aware of its properties and have knowledge about the product. Fig. 4, the frequency distribution curve shows the distribution of agreement and disagreement graph of the eight properties of Fibreglass material, which makes it advantageous over the convectional products among the people aware of FRP products.

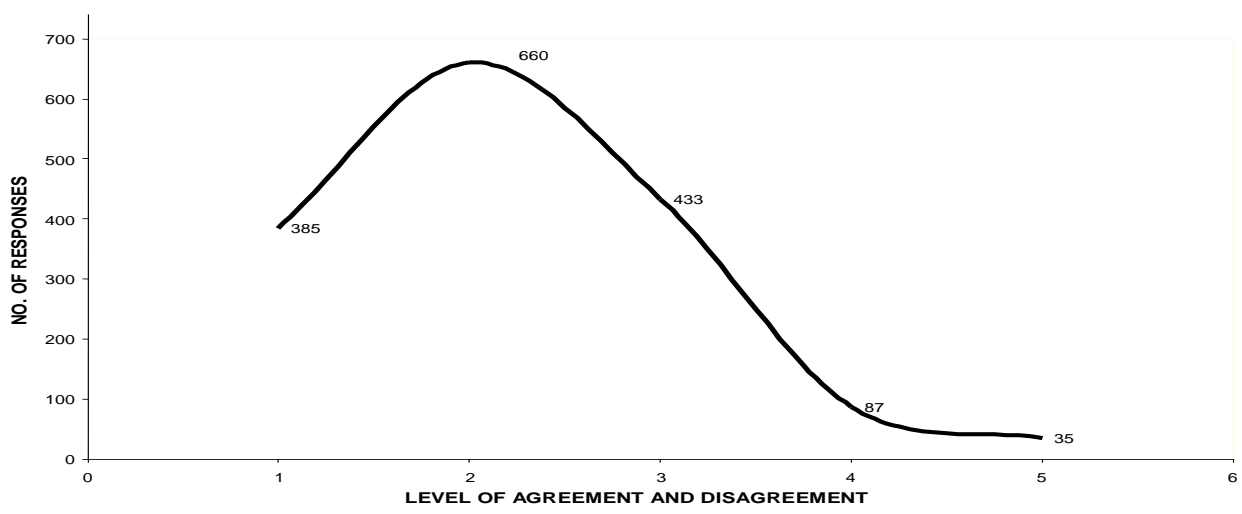


Green Marketing: Role of Psychographic Variables on Awareness and Purchase of FRP Product

INDEX

( $X$-axis)Numbers indicating level of agreement and disagreement:

$1=$ strongly agree $\quad 2=$ partially agree

$3=$ Indifferent attitude $\quad 4=$ partially disagree

$5=$ strongly disagree

\section{FIGURE 4: AWARENESS/ PRODUCT KNOWLEDGE (Agreement with FRP properties)}

Except awareness of a handful of products that is according to the data only five FRP products used for various application is more than $60 \%$, in spite of the fact that in the questionnaire these products were mentioned and the subjects were only supposed to tick the products of Reinforced Fiberglass Products which they were aware of. Hence, reflecting clearly the fact that the people of this region are not aware of the properties of these products. The awareness percentage of domes and mural is even less than $20 \%$; hence it is clear indication that in general people are not aware of its property of being moulded in any shape and any form, thereby depicting that the knowledge of the properties of FRP products are limited in the mind of the consumers of this region.

H After interpretation of the data of the research study, the hypothesis $\mathrm{H}$ is partially accepted.

\section{CONCLUSION}

Psychographic variables like perception, attitude, motivation and learning do have a significant effect on the awareness level. Whereas the type of personality trait reflected does not significantly affect the awareness level of FRP products. The purchase level of the customers is however effects by the personality trait. The increased percentage of purchase of FRP products is made by price conscious trait of the customers, hence making FRP products into prestige products.

Consumer behaviour research and analysis along with imagination, intuition, excitement and satisfaction is called for in the management and marketing of technologically revolutionarized products like polymers, particularly Reinforced Fibreglass plastics. The famous architect Lerrup [51] (1977, p. 156) explained the complex interaction between man and environment in very simple words, "We design things and things design us." It correctly explains the concept of environment design position prevalent in today's world too, with the application of versatile products like FRP.

On the other hand, the barriers of implementation of green strategies faced by the organizations are immense in India and cannot be erased without the support of the government. Radhakrishnan and Praveen [52], (2012, p. 59) concludes that, " Thus the identification of the local perception about the global sustainability frameworks and the intervention from local bodies of governance to mitigate the gaps in the sustainability perceptions could help the organizations achieve better environmental performance for their operations. Bhardi (2012, p. 1102), also concludes his paper with the following quote, "Regional governments must play an expanded role in disseminating valuable information and technology" Paper concludes that more awareness and assistance from government is required for implementation of practice of "Green Supply chain management" in India. The same is true for application of green marketing strategies for expansion in application of FRP products.

As far as growth of composite material is concerned worldwide, according to a recent article in the Civil Engineering and Construction Review (August 2012,), "Composite material technology is finding main stream acceptance across the globe. Composites are the materials of choice for many value / growth industries including medical, aerospace, defence, automobile, electrical renewable energy and mass transportation infrastructure. India is no exception to this trend." Hence Reed Exhibitions and Manch communication extend their partnership to new sector in India [53] (India Composite Show, 2012, p. 46).

In addition to this, it also states in another article [54] (Events and happenings, August 2012, p. 12) that "the use of glass has increased lately as new buildings seek to bring energy saving..... The usage of glass in green buildings is growing by $30-35 \%$ per annum." Hence glass consumption in green building is expected to grow rapidly because of it property of transparency which makes it as energy saving. But one of the major disadvantages of glass is that it is breakable. To overcome this disadvantage the glass fibres are mixed with composite material to make it into Fibreglass reinforced plastic or composite material, which is unbreakable. Moreover as expressed by Nifadkar and Dongre [55], (2012) "If India has to reduce its carbon emissions, it would mean a major reorientation of her energy strategy" (p.21).Hence the expansion of application of FRP products in various sectors can be enhanced by the implementation of green marketing strategies.

Fibreglass products are also looked upon by Nittobo as a part of their mission for spreading, "Technology today; tomorrow - an abundant society in harmony with nature." In the present times, in India especially, private sector plays a major role in achieving these objectives. As Phansalkar [56], (2005, p. 20) states, "now much more than ever the economic fate of the country depends on the vision dynamism and sagacity of the private sector." Above all the following quotes of Dr. Venkataswamy have expressed deeply an important element for the success of any research project. 


\section{"Intelligence and capability are not enough.}

There must be joy of doing something beautiful."

(As cited in Seshasayee, [57] 2007)

VII.

ACKNOWLEDGEMENTS

The authors wish to thank Messer Reliant Fibres, a Pioneer- Small Scale Industrial Unit for sowing the seed of this research project. They provided the Literature and reading material regarding fibreglass and its various products and properties, which was of immense value for the conception of this research study.

\section{REFERENCES}

[1] Dakode, Gaurav., \& Yerkari, Raju. (2012). Green Marketing - The Conceptual Framework. DMIETR Journal Of Management Outlook, 1 (Mar 2012). $414-417$.

[2] Jethani, Deepika., \& Uttarwar, Kartik. (2012). Value of Green Marketing in Today's Era Proc of 1st International Conference on Emerging Trends For Value Creation In the Era of Knowledge Economy-ELIXIR 2012, conference, Datta Meghe Institute of Management Studies, Nagpur, in association with Northern Illinois University, Illinois, United States and Lawrence University , Michigan. Retrieved February 17 \&18, 2012, 1371-1376.

[3] Kotlar, Philip., Kartajaya, Hermaan., and Seiawan, Iwan. (2010) . From Products to Customers to Human Spirit-Marketing 3.0 (Wiley India, New Delhi).

[4] Bhardi, Mahesh Ramesh. (2012). Problems faced by Indian organizations while implementing of Green supply chain Management (GSCM) practice in India. Proc. of 1st International Conference on Emerging Trends For Value Creation In the Era of Knowledge Economy-ELIXIR 2012, Datta Meghe Institute of Management Studies, Nagpur, in association with Northern Illinois University, Illinois, United States and Lawrence University, Michigan. Retrieved February 17 \&18, 2012, 1093-1102.

[5] Solaman, R. Michael, (2011). Consumer Behaviour, Buying, having and being 9th edition, (PHI Learning Private Limited, New Delhi- 110001, p 62)

[6] Schiffman, Leon G., , kanuf, Leslie Lazar \& Kumar, Ramesh S, Wisenblit, Joseph. (2010). Consumer Behavior (10 th Edition): (Pearson Education, Inc Chennai, Delhi, Chandigarh)

[7] U.S. Green Building Council (2002). Building Momentum - National Trends and Prospects for High Performance Green Buildings. Retrieved November 27, 2007, from http://www.greenbuildingpages.com

[8] A National Green Building Research Agenda. (2007, November). USGBC Research Committee. Retrieved November 27, 2007 from http://www. Ecological - Printer Friendly Page.htm \& http://www.USGBC Research \& Publications

[9] Sahasrabuddhe, H.S., , Bhole, A.G., and Deshpande,N.V. ( 2012), P.69) Application of green Building concept for an integrated Township Project - A Case study .International Journal of civil engineering and technology (IJCIET),3(1), January-June 2012, pp. 67-81.

[10] Kuthiala, Mala and Mahajan, Sadhana, (2012), Green Marketing: Role of demographic variables on awareness and purchase of FRP products. Interntional Journal of Scientific and engineering Research, 3(11) November 2012. (approved for publication)

[11] PTI. (2008, February 2). Buildings likely to be rated on energy saving mechanism. [Press release]. The Tribune, Real Estate, Chandigarh, p. 3.

[12] Wilson, Alex. (Ed.) (2001). An Energy, Environmental, and Economic Resource guide for Federal Facility Managers and Designers(2nd ed.). Produced by BuildingGreen, Inc., Brattleboro, Vermont. Retrieved November 27,2007,from: http://www.nrel.gov/doc/fyolosti/29267.pdf

[13] Masters, Gilbert M \& Ela, Wendell P. (2008). Introduction to Environmental Engineering and Science. (3rd Ed.).(New Delhi: PHI Learning Private Ltd.,) [14] Thapar, Mala. (2008). A Study on Consumer Behaviour Providing insight into potential application of Reinforced Fibreglass Plastic products in Construction and other activities. doctoral diss. Himachal Pradesh University, Shimla. 371 pp.

[15] Finger, H.B. (1972). Recent developments in building systems. Phil.Trans.R.Soc.Lond A. 272, 503-531 (1972) p. 503. Printed in Great Britain. Retrieved 22 February, 2008 from http://www.jstor.org/jstor/gifcvtdir

[16] Mc Garry, F.J. (1970). Building design with fibre reinforced materials. Proc, Roy. Soc.Lond.A.319, 59-68 (1970), p 59. Printed in Great Britain. Retrieved 22 February, 2008 from http://www.jstor.org/gifcvtdir

[17] Kurkjian, Charles R., and Matthewson, M. John. (2007). Mechanical Strength and Reliability of Glass Fibers. Specialty Optical Fibers Handbook, p. 735-781.

[18] Ryvkin, Michael., \& Aboudi, Jacob. (2007). A continuum approach to the analysis of stress field in the fibre reinforced composite with a transverse crack. International Journal of Solids and Structures, Vol. 44, Issue 21, 15 October, 2007, p. 6826-6841.

[19] Neto, Almir Barros da S. Santos., \& Rovere, Henriette Lebre La. (2007). Flexural stiffness characterization of fibre reinforced plastic pultruded beams. Composite structures, Vol. 81, Issue 2, November 2007, p. 274-282.

[20] Mouhmid, B., Imad, A., Benseddiq, N., Benmedakhène S., and Maazouz A. (2006). A study of the mechanical behaviour of a glass fibre reinforced polyamide 6.6: Experimental investigation. Polymer Testing, Volume 25, Issue 4, June 2006, P.544-552.

[21] Giraldi, A.L.F. de M., Bartoli, J.R., Velasco, J.I., \& Mei L.H.I. (2005). Glass fibre recycled poly(ethylene terephthalate) composites: mechanical and thermal properties. Polymer Testing, Volume 24, Issue 4, June 2005, Pages 507-512.

[22] NIIR - National Institute of Industrial Research, The Complete Technology Book on Fibre Glass, Optical Glass and Reinforced Plastics, 2007 (Asia Pacific Business Press Inc. New Delhi)

[23] Bakhshi, A.K., \& Sir Lal, Shankar. (2007). Electrically Conducting Polymers: Materials of the 21st Century. Proc. 2007 Seminar on RTSPC-II, Himachal Pradesh University. Retrieved March 23-24, 2007, from UGC -SAP National Seminar on Recent trends in Synthetic and Polymer Chemistry, p IT-7.

[24] Laroche, Esther Michel., Bergeron, Jasmin., and Barbaro-Forleo, Guido( 2001). Targeting Consumers who are Willing to Pay More for Environmentally. Journal of Consumer Marketing. Vol 18; No 6; Year 2001. p. $503-520$

[25] Bonini, Sheila., \& Oppenheim, Jeremy.(2008). Cultivating the Green Consumer. Stanford Social Innovation Review (Fall 2008), p. 56-61.

[26] D'Souza, Claire., Taghian, Mehdi., and Lamb, Peter (2006). An Empirical Study on the Influence on the Influence of Environmental Labels on Consumers, Corporate Communication: An International Journal, 11, no 2 (2006), 162-173.

[27] Yam-Tang, P.Y., Chan, Ricky Y.K. (1998), Purchasing behaviours and perceptions of environmentally harmful products. Marketing Intelligence \& Planning., 16; (6); Year 1998. p. 356-362.

[28] Anjankar, Namrata A. (2012). Consumer buying behavior towards Eco- friendly products. DMIETR Journal Of Management Outlook, 1 (Mar 2012) 62-67 
[29] Ananth, Sashikaka. (1999). The Penguin Guide to Vaastu: The classical Indian Science of Architecture and Design ( A Penguin Book Non Fiction/Architecture New Delhi).

[30] Jose, Sujatha and Helena, H. Jane. (2012). Life cycle cost analysis of green construction: a comparison with conventional contruction. NICMAR Journal of Construction Management, XXVII (1), Jan- March 2012, 36-47. [31] Chopra, Abha., \& Marriya, Shruti. ( 2012)., Green Marketing: A Behaviour Analysis Of Consumers. DMIETR Journal Of Management Outlook, 1 (Mar 2012) 792-813

[32] Kotler, Philip., Keller, Kevin Lane, Koshy, Abraham and Jha, Mithileshwar. (2009) Marketing Management - A South Asian Perspective. 13th edition, (Pearson Education, Inc. p. 80).

[33] Ottman, Jacquelyn A., Stafford, Edwin R.,and Hartman, Cathy 1. (2006). Avoiding green Marketing Myopia. Environment - Science and policy for sustainable development,s(June, 2006) Volume 48, Number 5, 22-36.

[34] Kuthiala, Mala.,(2012). Framing Marketing Strategy for Fibreglass Reinforced Plastic (FRP) Products. DMIETR Journal Of Management Outlook, 1 (Mar 2012). 609-626.

[35] Hair, Joseph F JR., Bush, Robert P., and Ortinare, David J. (2008). Marketing Research: within a changing information environment (3rd. Edition), (Tata Mc Graw-Hill edition, (p. 175).)

[36] Sănchez De Antuňano Barranco, Jorge.M.A.(2005).Visualizing Complex designed environments. doctoral diss. Union institute of University.

[37] Sathish, Dhivya., and VenkatramarRaju, D. 2012. Satisfaction of buyers towards retail outlets. International Jounal of Management (IJM) Volume 3, Issue 1, January-April (2012). p 115- 120)

[38] Kuthiala, Mala.,(2012), Demographicaal effect on awareness and purchase of FRP Products, Proc of 1st International Conference on Emerging Trends For Value Creation In the Era of Knowledge Economy-ELIXIR 2012, Paper presented and awarded at the 2012 conference, Datta Meghe Institute of Management Studies,Nagpur, in association with Northern Illinois University, Illinois, United States and Lawrence University , Michigan. Retrieved February 17 \&18, 2012, 824-852.

[39] Singh, Mian Goverdhan (1997), Himachal Pradesh, History, culture and economy.( Minerva Book House, Shimla).

[40] Kansal, Mani., \& Paliwal, Puja. (2012). Role Of Social And Environmental Concerns In Gaining A Leading Edge Over Competitors. DMIETR Journal Of Management Outlook, 1 (Mar 2012). 872-885.

[41] Summary of table on houses, households, Amenities and Assets of Himachal Pradesh. (2001). Census of India. Table H-3A India: Himachal Pradesh Summary. Table S02-004: Distribution of census houses by predominant material of roof. Directorate of Census operations, Himachal Pradesh, Shimla (p. 6).

[42] Summary of table on houses, households, Amenities and Assets of Himachal Pradesh. (2001). Census of India. Table H-3B India: Himachal Pradesh Summary. Table S02-005: Distribution of census houses by predominant material of wall. Directorate of Census operations, Himachal Pradesh, Shimla (p. 8).

[43] Summary of table on houses, households, Amenities and Assets of Himachal Pradesh. (2001). Census of India. Table H-3C India: Himachal Pradesh Summary. Table S02-006: Distribution of census houses by predominant material of floor. Directorate of Census operations, Himachal Pradesh, Shimla (p.9).

[44] Kuthiala, Mala.,(2012). Framing Marketing Strategy for Fibreglass Reinforced Plastic (FRP) Products. Proc of 1st National Conference on Indigenous Management practices-PANACEA- 2012. 46, Datta Meghe Institute of Engineering, Technology and Research, Wardha, in association with Indian society of Technical education, New Delhi. Retrieved March 2, 2012,

[45] Darten, William R., and Perrcault Jr, William D., (1975). Identifying Interurban shoppers multi product purchase pattern and Segmentation Profiles. Journal of Marketing Research, February 1975, p. 51-60.

[46] Singh, Mian Goverdhan. (1988). Himachal Pradesh, History, culture and economy ( Minerva Book House, Shimla).

[47] Erickson, Gary M. and Johny K. Johansson (1985), "The Role of Price in Multi-Attribute Product Evaluations," Journal of Consumer Research, 12 (September), 195-199.

[48] Lichtenstein, Donald R., Peter H. Bloch and William C. Black (1988), "Correlates of Price Acceptability," Journal of Consumer Research, 15 (September), 243-252.

[49] Tellis, Gerard J. and Gary J. Gaeth (1990), "Best Value, Price-Seeking, and Price Aversion: The Impact of Information and Learning on Consumer Choices," Journal of Marketing, 54 (April), 34-45.

[50] Lichtenstein, Donald R., Ridgway, Nancy M., and Netemeyer, Richard G. (1993). Price Perceptions and Consumer Shopping Behavior: A Field Study. Journal of Marketing Research, 30 (May), 234-245.

[51] Lerrup, L. (1977), Building the unfinished. (Beverly Hills: Sage Publications).

[52] Radhakrishnan, R., and Praveen, A. ( 2012) Sustainability Perception on wastewater treatment operations in urban areas of the Developing world , International Journal of civil engineering and technology (IJCIET),3(1), January-June 2012, pp. 45-61.

[53] India Composite show 2012: Civil Engineering and Construction Review (August 2012, p.46).

[54] Events and happenings: glass consumption - in green buildings to grow rapidly-Civil Engineering and Construction Review ( August 2012), Vol. 25 No. 8., p. 12.

[55] Nifadkar, Renuka S., \& Dongre, Anil P. Study on India,s Perceptions, positions, polices and possibilities with reference to climatic change: the Driving Force of Environmental Stress. Proc of 1st International Conference on Emerging Trends For Value Creation In the Era of Knowledge Economy-ELIXIR 2012, Datta Meghe Institute of Management Studies,Nagpur, in association with Northern Illinois University, Illinois, U S and Lawrence University, Michigan. Retrieved February 17 \&18, 2012, 19-35. [56] Phansalkar, Sanjiv. SI. (2005). Opportunities and strategies for Indian Business: Preparing for Global India. (New Delhi/ Thousand Oaks/London: Response books, a division of Sage publications.)

[57] Seshasayee, R. (2007). Advantage India. Vikalpa, volume 32, No.2 April-June 2007. 